\title{
Metonymic objects, cultural practices and narrative repair: Sri Lankan responses to the Indian Ocean tsunami
}

Journal of Health Psychology 2015, Vol. 20(7) 974-983 (C) The Author(s) 2013

Reprints and permissions: sagepub.co.uk/journalsPermissions.nav DOI: $10.1177 / 1359105313504442$ hpq.sagepub.com

@SAGE

\section{Shemana Cassim, Ottilie Stolte and Darrin Hodgetts}

\begin{abstract}
The 2004 Indian Ocean tsunami resulted in a tragic loss of life and immense suffering. This article explores the ways in which a group of people from Sri Lanka worked to address the disruption to their life narratives caused by the loss of loved ones. We go beyond a focus on 'talk' in narrative research in health psychology to explore the importance of material objects in sustaining continued bonds with the deceased. This article provides an alternative to the tendency in mainstream psychology to pathologise grief and highlights the importance of culturally patterned responses to disaster.
\end{abstract}

\section{Keywords}

cultural practice, disaster, material objects, narrative recovery, tsunami

In Sri Lanka, the Indian Ocean tsunami claimed over 30,000 lives, 20,000 sustained injuries and 500,000 people were displaced. Health and community psychologists have a long-standing interest in such disruptions to life. However, dominant approaches to such events are often culturally blind in assuming that Judeo-Christian inspired approaches to understanding death, injury and recovery are universally applicable. This article draws upon Buddhist understandings of death and grief as core elements of renewal in life. We do so in order to understand how particular material objects, including monuments, songs, artwork and souvenirs can enable people to memorialise, re-member and recover from disasters. Further insights are drawn from research into illness narratives and the arts, which suggests that creative expressions are instrumental in initiating healing processes that allow lives to continue despite tragedy.

Psychological research into natural disasters primarily focuses on diagnosing abnormalities and resolving trauma, anxiety, depression and grief (de Silva, 2006; Madrid and Grant, 2008; Nikapota, 2006). In practice, our disciplinary engagements have been limited by the dominance of overly narrow and individualistic therapeutic approaches. The cultivation of a sense of detachment from the deceased and acceptance of the 'reality' of death are presented as

University of Waikato, New Zealand

\section{Corresponding author:}

Shemana Cassim, School of Psychology, University of Waikato, Private Bag 3105, Hamilton, New Zealand.

Email: gsc7@waikato.ac.nz 
central to restoring an individual's functioning in life (Davies, 2004; Freud, 1961; Nastasi et al., 2011). Psychologists have all but ignored the function of culture and material objects in human responses to disaster. More attention needs to be paid to the importance of diversity in recovery in the context of everyday life and how survivors move through grief in culturally patterned ways that enable them to live with loss.

Recent psychological narrative research on recovery following illness foregrounds the importance of narrative reconstruction (Radley, 2009). The objective is not to make detachment a guiding principle, but to embrace and live with events, no matter how traumatic. This orientation is also useful in informing our understanding of how disasters disrupt life projections and cause uncertainty and discomfort, and how people work to regain control over their lives (cf. Bury, 1982; Murray, 2000; Radley, 2009; Tuohy and Stephens, 2012). In developing this orientation, it is important to note that personal life narratives are not strictly one's own. Life narratives that provide a mode for organising and obtaining a sense of meaning for one's experiences are produced from various socio-cultural resources that are refined through the dialectics of everyday life (Billig, 2008; Hodgetts et al., 2010). Personal narratives are generated from communal level narratives held within communities (Murray, 2000; Rappaport, 2000). According to Sarbin's (1986) narrative principle, 'human beings think, perceive, imagine, interact and make moral choices according to narrative structures' (p. 9), which are shared with others. In the case of serious illness, the steady flowing continuity of life narratives can be disrupted, which challenges not only the past but also future hopes, plans and ambitions (Bury, 1982). Such disruptions can necessitate people to reassemble their very sense of self and life. Their efforts at restorying themselves are given form in language, the arts and material practices (Radley, 2009).
Work on bereavement and grief (Glazer and Marcum, 2003; Witztum and Malkinson, 2009) provides particular insights into how people reassemble their life narratives after experiencing a disaster. Narrative reconstruction via artistic endeavour enables people to render events and experiences tangible. Creative works can act as transitional objects that attach people to the memory of loved ones lost (Witztum and Malkinson, 2009). Moreover, through artistic expression the tangible nature of a material object can be instrumental in initiating feelings that are often inaccessible. This can further elicit episodic moments of deep affective relevance (Beckstead et al., 2011; Glazer and Marcum, 2003).

The role of such material objects and related practices in narrative repair requires further exploration within health psychology. We draw upon the concept of metonymy to explore the significance of material objects in Sri Lankan responses to the tsunami. The term metonym refers to a single (material) object that represents a larger whole. Particular metonyms are created when cultural and personal processes ascribe symbolic meanings to specific objects (Beckstead et al., 2011). Objects such as monuments, shrines, paintings, photographs and souvenirs are not only physical but socio-cultural products that shape and inform personal and community narratives in tangible ways (Morgan and Pritchard, 2005). These objects can elicit thoughts, histories, memories, understandings and feelings (Beckstead et al., 2011). As Webmoor and Witmore (2008) note, 'things are an entangled aspect of what it is to be human and many achievements of many people ... are always folded together into a thing' (p. 59). These are not static processes. While objects such as memorials can be intended to preserve history, they are also constantly recreated and reminisced through ongoing encounters. Grieving friends and relatives often seek a physical location and a material entity around which to rebuild a tangible connection with deceased loved ones. A simple touch or trace of the names inscribed on a 


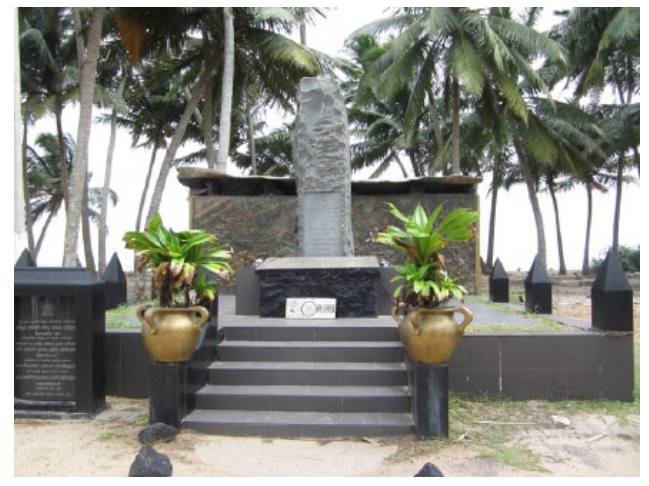

Figure I. Tsunami monument in Hikkaduwa.

memorial can have the quality of invoking the memory of those lost (Stephens, 2007). Metonymic objects can become a means through which people learn to live with grief and loss.

\section{The present study: location and approach}

This place being studied in this research is located in Hikkaduwa (population 130,000), a small coastal town located in the Southern Province of Sri Lanka. The first author (S.C.), a Sri Lankan female, travelled to Sri Lanka for a period of 7 weeks to focus on the everyday practices of narrative repair in Hikkaduwa. Community and indigenous psychologists have emphasised the importance of investing time in participatory processes and establishing relationships with research participants (cf. Cassim et al., in press; Pe-Pua, 2006; Scheib and Lykes, 2013). Establishing mutual trust through lengthy informal and formal interactions was especially important during the fieldwork of this study due to the personal nature of the life narratives. The expression of feelings, direct verbal communication and the sharing of personal information are counter to the cultural norms of many Asian cultures (Fernando, 2009). S.C.'s knowledge of and ability to participate in cultural practices with participants, was crucial to both the conduct of the research and interpretation of participant accounts and practices (cf. Nastasi et al., 2011).

The tsunami was of particular relevance to this community due to the large loss of life and extensive damage in the town. A particularly prominent public memorial (see Figure 1) was erected in the town to depict the horror of the tsunami and to remember those lost in the disaster (Perera, 2009). This article is concerned less with such public monuments and more with smaller scale personal objects that have attracted less scholarly attention and which participants preferred to use within their own practices of remembrance and narrative repair.

A core group of research participants comprised three males and two females, ranging in age from 37 to 57 years, who had lost homes, family and friends. All five participated in three in-depth interviews utilising visual, place and object-related methods. Repeat encounters, goalong interviews and discussions of material objects and images helped draw out their situated stories and allowed S.C. to view and photograph the various things and places of significance to them.

Analysis of the interviews and fieldnotes took into account how people organise their beliefs and social practices within a particular social setting, the interpersonal processes that occur within a situation and the relevance of various culturally patterned practices to the healing of their life narratives. Recorded interviews were transcribed in Sinhalese. Preliminary analysis was carried out in Sinhalese as means of preserving cultural understandings and concepts not necessarily familiar to the English language. Methods of holistic structural analysis and thematic analysis (Lieblich et al., 1998) were used to examine the transcripts. Upon establishing initial themes and patterns, the interviews were translated into English for further interpretation. A combination of these analytic methods allowed for the recognition of the contours of the participants' life stories in conjunction with the sociocultural context from which their narratives derive meaning (Rappaport, 2000). 
Our analysis was conducted from a phronetic knowledge framework (Flyvbjerg et al., 2012), which involves the interpretation of people's everyday situated and lived knowledge. This approach emphasises collaboration with participants by drawing on their experiential knowledge and expertise. Instead of simply 'giving voice' by restating what participants have said, there is an emphasis on interpretation and the co-creation of knowledge (Radley, 2009). This involves the mixing of participant narratives and actions or practices with the researchers' interpretations and existing literature in the analytic process. The research was also underpinned by a focus on what people do in the context of their daily lives, and how meaning is created in the act of 'doing' rather than as an independent state of mind (cf. Hodgetts et al., 2010). Consequently, meaning is not restricted to a particular object or set of practices, but is generated by social actors in the multifaceted relationships and interactions that occur in everyday life.

\section{Disruptions to life narratives - negative and positive change}

In his discussion of biographical disruption, Bury (1982) links three aspects of disruption to the unfolding of an illness, which can equally be applied to the present context. First, Bury considers the breaching of common-sense boundaries. This stage involves attention to assumptions or actions not usually brought into consciousness. Prior to the tsunami, the people of Hikkaduwa did not perceive the ocean as a threat. Many of the participants expressed disbelief that their beloved ocean stole their lives. The resulting shock and confusion was twofold: not only were they forced to cope with the sudden loss of their family and friends, but they were forced to view the otherwise familiar ocean as an alien and dangerous entity. Nadhee, a 42-year-old female homemaker, states,

At the start we just could not understand how this could happen. What did we do to deserve this?
We lost everything. How could we possibly move on from this? Who do we go to for help? Everyone was affected. Some people lost their children to the waves. That is not how life is supposed to go. Parents should not have to bury their children. It all felt so unreal. Like a dream.

In Bury's (1982) words, Nadhee was at a point where her 'common-sense assumptions' had lost their 'grip', and yet 'alternative explanations' had not readily presented themselves (p. 171). Nadhee was unsure of what to do. This confusion did not last. As time passed, participants learned to move on with life. This recognition marks the end of the initial stage.

In the second stage, participants engaged in processes of self-reflection. As part of this process, they questioned their identities, and contemplated reshaping their personal life narratives (Bury, 1982; Tuohy and Stephens, 2012). The onset of a tragedy can challenge not only the past but also future hopes, plans and ambitions, causing individuals to rethink their lives, reminding them of the complexities of life (Radley, 2009). Priyani, a 37-year-old female, lost her parents to the tsunami and explains how she had to rapidly learn independence and focus on rebuilding her parents' destroyed home:

I changed a lot after the tsunami. The way I think and the way I look at life. I was 29-years-old when the tsunami hit. But within a year after I lost my parents to the waves, I felt like I had aged by 70 years. I lived with my parents and they used to look after me. I had no responsibilities at all. I was treated, and I behaved like an 18-year-old. After my parents were taken from me, I was forced to grow up. I was confronted with all these household chores and responsibilities, which I had never even thought of before. [...] My mother wanted me to be a teacher just like herself, and that was what I was studying to be. But after the tsunami I couldn't continue ... I realised that was my mother's dream. Not mine.

Changes such as these not only altered the self-concepts of the participants, they also occurred in terms of their lifestyles, jobs and 
responsibilities. For example, Priyantha, a 57-year-old male, lost his wife, daughter and father-in-law to the tsunami. While he had recently remarried and had a son, he still mourned his lost family. Like many men in Hikkaduwa, Priyantha was a coral miner; however, after the tsunami, he found work in the coconut industry. Priyantha viewed the tsunami as a turning point in his life. As Radley (2009) suggests, survival becomes a condition, rather than a precondition, of one's need to reexamine how he or she arrived at this point in life. The onset of the tragedy not only caused significant disruption to the continuous flow of the life narratives of our participants, it also enabled them to re-story their life narratives, allowing other plots to become possible.

The third aspect of Bury's (1982) response to narrative disruption is evident in the emergence of a response to disruption involving the mobilisation of shared narrative resources. Participant life narrative reconstructions are formed within broader socio-cultural narratives. Sri Lanka is a predominantly Buddhist nation, and consequently all our participants believed in the temporality of life and the need to face adversity in order to reach enlightenment. Buddhists emphasise the concept of dukkha, which translates to suffering and a sense of dissatisfaction and anxiety (Mikulas, 2007). Emphasis is placed on the impermanence of suffering, that it is subject to change (Wada and Park, 2009). In the context of grief and loss, this recognition may provide the bereaved with a sense of acceptance and the strength to endure their pain or loss, while providing spiritual and emotional growth (Wada and Park, 2009). Although one can understand notions of acceptance at an intellectual level, experiencing hardship first-hand is still difficult to accept and live with. Over time, however, the experience of loss can also become a source of strength as Priyani states,

Today I am strong. I am not afraid to live life, because of the strength I gained through losing everything and everyone to the waves. I don't let anything or anyone bring me down. My goal is to make the best of the life I have now.

This quote illustrates Priyani's ability to move beyond loss and grief to make the most of the gift of life. The tsunami provided an opening for participants to change, and acted as a reawakening agent giving them a second chance at life. Experiences of significant loss enabled them to view their vulnerabilities, and even their whole lives with increased clarity (Wada and Park, 2009).

Disaster psychology focuses primarily on the negative aspects of tragedies. Yet, there are also positive aspects to rebuilding lives. For example, the tragedy opened up a range of job opportunities as increased numbers of men and women joined non-governmental organisations in the aftermath of the tsunami (de Mel et al., 2010). Ajith, a 46-year-old male, explains how their future in Hikkaduwa is now more promising:

\begin{abstract}
On one hand the tsunami was sad, because a lot of us lost our homes and families. But on the other hand it did bring some good ... There are actually more jobs available in these parts now, and our children are more motivated to study well and earn for their families.
\end{abstract}

Such extracts reflect the cultural practice in Hikkaduwa of looking for positive consequences from tragedy, which became central to narrative recovery for participants. The future is viewed with hope, and this aids the acceptance of the grief and loss the surviving community has had to endure. Buddhist beliefs provided participants with a template for working through pain and loss and helped them find healthy ways of living with their grief. Participant responses invoke the need to consider strategies through which such communities can construct new meanings and ways of being. Narrative repair recreates a sense of order to life and provides meaning as well as dignity to even the most painful experiences by providing a sense of continuity between the past and the future (Rappaport, 2000). 


\section{Metonymic objects as agents for narrative reconstruction}

Material objects such as monuments, shrines and artworks can facilitate the re-storying of fractured life narratives (Beckstead et al., 2011; Radley, 2009) and can provide focal points for renewing bonds with the deceased. This section explores the metonymic function of various objects from state-funded monuments to a child's dress and windowpane in participant responses to the tsunami. We briefly consider participants restrained use of public monuments and then focus on the personal objects which they present as being central to their everyday responses and narrative reconstructions.

Tsunami memorials in Hikkaduwa were commissioned by governmental agencies. Members of the community had no input into the design or location of these monuments. They functioned as contested objects that were associated with broader socio-political events in Sri Lankan history, which restricted their use by our participants as everyday focal points for remembrance (cf. Jorgensen-Earp and Lanzilotti, 1998). In light of the recent civil war, these objects represent state control and conflict. Public monuments served more to remind local people of the State's control in their lives, rather than engaging them in their own processes of grieving and recovery. Moreover, public expressions of grief and pain run against the cultural norms of the local community (Fernando, 2009). All of the participants stated that they gathered at the public tsunami monuments only on the anniversary of the tragedy. They considered the structures themselves impersonal, and felt a sense of detachment in relation to them. As Ajith explains,

We don't go there much, only at each anniversary of the tsunami. [...] We didn't build those monuments ourselves, so we don't really feel anything towards them.

Although the people of Hikkaduwa expressed little connection to the official tsunami monuments, this did not mean that they had severed bonds with the tragedy. Instead, expressions of grief were enacted on a more personal scale. Private memorials were common in this tsunami stricken community. Three participants had private shrines in their homes. For example, Nadhee was able to reach safety with her husband and daughter during the disaster; however, she lost many family members including her mother, father, brother and sisterin-law. Nadhee and her husband constructed a small monument at the site of the destroyed house, and she also has a shrine in the hallway of her new house: ${ }^{1}$

The shrine makes me feel like my parents are right there with me. I see them every morning when I go to light the lamps at the pictures and place flowers there. I talk to them, tell them my plans for the day, and I wish them well in their next life.

The maintenance of a portrait of the deceased, upon which flower garlands are placed and oil lamps are lit, is a common practice among Sri Lankan Buddhists, forming a religious as well as a cultural norm. However, these shrines served an additional function. Similar to war memorials, these personal shrines also functioned as a way by which the bereaved re-member those lost. The portraits acted as a substitute for the material existence of a body, and become a medium for communication between the living and the dead (Stephens, 2007).

Within this community, another way of expressing grief privately was through the arts. Practices involving the production of artwork enable the bereaved to continue bonds with the deceased. The repair of Priyani's life narrative following the tsunami commenced when she started composing songs and poems such as the one below:

Mother and father, I ask for forgiveness for not being able to save you the day the ocean encroached the land. The tears that started flowing from my eyes that day are still flowing today. I do not value any other love aside from yours. You, the sun and moon of my world were 
extinguished. Your youngest daughter is left on her own today. The hopes and dreams you had for your youngest daughter, did not sink along with the waves. The day those hopes and dreams are fulfilled, you will be smiling down from the world of the Gods. That is why I am still alive.

Artworks, much like shrines, can function as transitional entities that allow the living to speak to the deceased. The benefit of reconstructing her life narrative through the composition of poems is evident in how Priyani reveals her determination to live for her parents, to honour their hopes and dreams. One song she wrote was recorded by a famous local singer and gained national radio and television airplay. This example supports Radley's (2009) argument that poems can serve 'as vehicles for coming to terms, for ways of re-entering the world of the healthy' (p. 128). Similar to the function of illness narratives, poetry served as a healing agent enabling Priyani to come to terms with her situation.

A number of material objects were instrumental in allowing members of the Hikkaduwa community to establish a sense of connection to lost loved ones and to cultivate hope for the future. Connections such as those mentioned above seemed to not only occur between the living and the dead in this context but also between past and present. For Nadhee, an article of clothing she preserved from that fateful day served not only as evidence of existence but also as proof of loss (see Figure 2). This article of clothing that was worn by her daughter on that fateful day will be used in the future to materialise the event for her child. The preservation of her daughter's dress provided ontological security in her survival. As Nadhee explained,

This was the dress my daughter was wearing when the tsunami hit. Yes she was only a baby back then. I saved it to remember. Maybe she will forget, because she was so young. But one day she will want to know what happened. And this will help me explain the story to her. I can teach her that we should appreciate this life that was

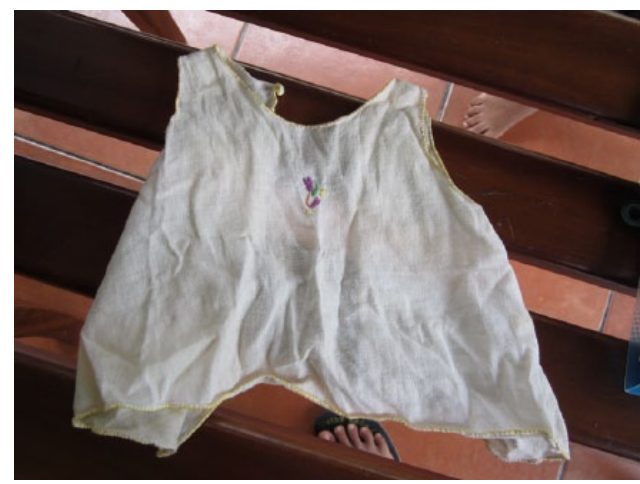

Figure 2. Nadhee's daughter's dress.

given to us. We need to make the most of it, because we never know when it will be taken away.

The willingness to give an aesthetic form to a painful image or fragment of memory from the past, such as a disruptive event, can be pivotal to the process of psychological healing. Objects can be used as reference points that maintain links to one's past, present and future life (Radley, 2009). Expanding this process, Ajith perceived the tsunami as a landmark event, differentiating his old and new life. On constructing his new house following the tsunami, Ajith salvaged a single windowpane from the rubble that was his old home:

Our whole house was destroyed by the waves. But later one of our neighbours found a single windowpane in the rubble. Even though everything else was completely wrecked, that windowpane remained. So I saved it. And we fixed it in the new house [...]. We built the new house on the foundation of the old one. It's just the windowpane that remains from our old life. As a reminder you know? [...] Something like the clothes we wore on the day. Say a suit or something, can get lost with time. But a window can last. We can't lose or misplace something like that.

Ajith's decision to use the old windowpane and to build a new house on the foundation of the old house was his way of acknowledging 
the continuity of life. Despite a conscious knowledge that everything and everyone around him had changed, including himself, the windowpane provided a sense of continuity between the past and the present. Furthermore, this object had the concrete permanence of a monument and a sense of being able to avoid further loss. Ajith's indication that this windowpane could not be misplaced implies that he did not wish to forget or severe ties with his past, and instead sought a constant reminder of his old life.

\section{Conclusion}

Narrative health research (Bury, 1982; Murray, 2000; Radley, 2009) foregrounds how illness can disrupt a person's life story, requiring an active response as part of the recovery process. We have reapplied these ideas to inform our understanding of human responses to natural disasters. There is also a substantial body of research into the role of public monuments in remembrance (Beckstead et al., 2011; Morgan and Pritchard, 2005; Stephens, 2007; Webmoor and Witmore, 2008), the findings of which were only partially confirmed in the context of Hikkaduwa. Participants placed more emphasis on the use of smaller personal monuments and in the process confirmed the relevance of artwork in narrative recovery (Radley, 2009).

Central to this study is the metonymic function of material objects. Maintaining bonds with lost loved ones through the preservation of objects such as clothing, the composition of poetry and carrying out rituals facilitates healing. Material objects and associated practices facilitate the repair of life narratives by acting as transitional entities, providing media through which loved ones can communicate and maintain bonds with the deceased (Glazer and Marcum, 2003; Green, 2008; Stephens, 2007; Witztum and Malkinson, 2009). The seemingly mundane everyday practices of our participants foreground the importance of particular 'things' and reflect the need for health psychologists to develop better understandings of how people can respond agentively to tragedy. For example, the poems composed by Priyani give form to her grief. This is not merely the work of a lonely thinker, it is a 'work of loss' that draws on shared and culturally patterned understandings of what it means to grieve for the people we care about. Priyani's poems not only allow her to give substance to her grief but also to connect her personal experiences to much broader processes of life that affect us all.

Research into collective memory also suggests that "memory is not only "stored in brains" but rather distributed through social artefacts and cultural tools' (Beckstead et al., 2011: 195). In addition to acting as markers for social events, objects become instrumental for understanding the past and come to embody stories relating to past events or narratives (Beckstead et al., 2011). Objects such as a child's dress can acquire a 'secular sacred character' as more than symbols of the past (Morgan and Pritchard, 2005). These objects become metonyms of past events and aid people in re-establishing connections, not only to the deceased, but also to past identities and lives.

Our participants' actions of remembrance through the construction and use of material objects are congruent with Buddhist perceptions of life, death and rebirth as being part of a cycle of renewal (cf. Aronson, 2004; Wada and Park, 2009). Reflecting a phronetic approach to analysis, the local Buddhist beliefs inform our interpretation of the importance our participants place on continuing bonds with the deceased in this world. In contrast to dominant Judeo-Christian notions of the finality of death in orthodox health psychology, for Buddhists death does not mark the end of life in this world. Rather, death is a part of life, thereby reinforcing the notion of continued bonds, so that the bereaved 'learn to live with the dead in a new way' (Green, 2008: 189). Everyday acts that invoke grief and enable re-membering are encapsulated in practices such as alms givings or dhaana, lighting oil lamps and laying flowers in significant places. Further, the allocation of a time and place for such acts of private 
mourning, as well as locating grief in symbolic objects or metonyms, provides people with a way to materialise their grief. Grief and loss are given permission to exist. In being present with the grief each day, loss can become less overwhelming.

\section{Funding}

This research received no specific grant from any funding agency in the public, commercial or not-forprofit sectors.

\section{Note}

1. Pictures of the shrines could not be taken as they comprised portraits of deceased family members, and were therefore very personal to participants.

\section{References}

Aronson HB (2004) Buddhist Practice on Western Ground: Reconciling Eastern Ideals and Western Philosophy. Boston, MA: Shambhala Publications.

Beckstead Z, Twose G, Levesque-Gottlieb E, and Rizzo J (2011) Collective remembering through the materiality and organization of war memorials. Journal of Material Culture 16(2): 193-213.

Billig M (2008) The Hidden Roots of Critical Psychology. London: SAGE.

Bury M (1982) Chronic illness as biographical disruption. Sociology of Health \& Illness 4: 167-182.

Cassim S, Hodgetts D, and Stolte O (in press) Cultural consideration and mixed methods for psychological research: A Sri Lankan perspective. In: Rineheart R and Emerald E (eds) Tensions and Positionings: Ethnographies in Pan Pacific Research.

Davies R (2004) New understandings of parental grief: Literature review. Journal of Advanced Nursing 46(5): 506-513.

de Mel N, Ruwanpura KN, and Samarasinghe G (2010) After the Waves: The Impact of the Tsunami on Women in Sri Lanka. Colombo, Sri Lanka: Social Scientists' Association.

de Silva P (2006) The tsunami and its aftermath in Sri Lanka: Explorations of a Buddhist perspective. International Review of Psychiatry 18(3): 281-287.
Fernando DM (2009) Group work with survivors of the 2004 Asian Tsunami: Reflections of an American-trained counsellor. The Journal for Specialists in Group Work 34(1): 4-23.

Flyvbjerg B, Landman T, and Schram S (2012) Real Social Science: Applied Phronesis. Cambridge: Cambridge University Press.

Freud S (1961) Mourning and melancholia. In: Strachey J (ed.) The Standard Edition of the Complete Psychological Works of Sigmund Freud. London: Hogarth Press, pp. 239-260.

Glazer HR and Marcum D (2003) Expressing grief through storytelling. Journal of Humanistic Counseling 42(2): 131-138.

Green JW (2008) Beyond the Good Death: The Anthropology of Modern Dying. Philadelphia, PA: University of Pennsylvania Press.

Hodgetts D, Stolte O, Chamberlain K, et al. (2010) The mobile hermit and the city: Considering links between places, objects, and identities in social psychological research on homelessness. British Journal of Social Psychology 49: 285-303.

Jorgensen-Earp CR and Lanzilotti LA (1998) Public memory and private grief: The construction of shrines at the sites of public tragedy. Quarterly Journal of Speech 84: 150-170.

Lieblich A, Tuval-Mashiach R, and Zilber T (1998) Narrative Research: Reading, Analysis and Interpretation. Thousand Oaks, CA: SAGE.

Madrid PA and Grant R (2008) Meeting mental health needs following a natural disaster: Lessons from hurricane Katrina. Professional Psychology: Research and Practice 39(1): 86-92.

Mikulas WL (2007) Buddhism and western psychology: Fundamentals of integration. Journal of Consciousness Studies 14(4): 4-49.

Morgan N and Pritchard A (2005) On souvenirs and metonymy: Narratives of memory, metaphor and materiality. Tourist Studies 5(1): 29-53.

Murray M (2000) Levels of narrative analysis in health psychology. Journal of Health Psychology 5: 337-347.

Nastasi BK, Jayasena A, Summerville M, et al. (2011) Facilitating long-term recovery from natural disasters: Psychosocial programming for tsunami-affected schools of Sri Lanka. School Psychology International 32(5): 512-532.

Nikapota A (2006) After the tsunami: A story from Sri Lanka. International Review of Psychiatry 18(3): 275-279. 
Pe-Pua R (2006) From decolonizing psychology to the development of a cross-indigenous perspective in methodology: The Philippine experience. In: Kim U, Yang K and Hwang K (eds) Indigenous and Cultural Psychology: Understanding People in Context. New York: Springer, pp. 109-137.

Perera A (2009) In Sri Lanka, tsunami anniversary inspires mixed reactions. Available at: http://www. time.com/time/world/article/0,8599,1949982,00. html (accessed 1 November 2011).

Radley A (2009) Works of Illness: Narrative, Picturing and the Social Response to Serious Disease. Ashby-de-la-Zouch, England: InkerMen Press.

Rappaport J (2000) Community narratives: Tales of terror and joy. American Journal of Community Psychology 28: 1-24.

Sarbin TR (1986) The narrative as a root metaphor for psychology. In: Sarbin TR (ed.) Narrative Psychology: The Storied Nature of Human Conduct. New York: Praeger, pp. 3-21.
Scheib HA and Lykes MB (2013) African American and Latina community health workers engage in PhotoPAR as a resource in a post-disaster context: Katrina at 5 years. Journal of Health Psychology 18(8): 1069-1084.

Stephens J (2007) Memory, commemoration and the meaning of a suburban war memorial. Journal of Material Culture 12(3): 241-261.

Tuohy R and Stephens C (2012) Older adults' narratives about flood disaster: Resilience, coherence, and personal identity. Journal of Aging Studies 26: $26-34$.

Wada K and Park J (2009) Integrating Buddhist psychology into grief counselling. Death Studies 33: 657-683.

Webmoor T and Witmore C (2008) Things are us! A commentary on human/things relations under the banner of a 'social' archaeology. Norwegian Archaeological Review 41(1): 531-570.

Witztum E and Malkinson R (2009) Examining traumatic grief and loss among Holocaust survivors. Journal of Loss \& Trauma 14: 129-143. 